\title{
Violência contra a mulher: levantamento dos casos atendidos no setor de psicologia de uma delegacia para a mulher ${ }^{1}$
}

\author{
Violence against women: survey of the cases \\ seen in the psychology service at a \\ women's police station
}

\author{
Lila Maria GADONI-COSTA² \\ Ana Paula Noronha ZUCATTI ${ }^{3}$ \\ Débora Dalbosco DELL'AGLIO'
}

\begin{abstract}
Resumo
Este trabalho apresenta um levantamento dos casos atendidos no setor de Psicologia de uma Delegacia para a Mulher, em município da região metropolitana de Porto Alegre, no período de 2006 a 2008. A amostra empírica compreende 351 mulheres, com idades entre 12 e 78 anos, com relato de violência física, psicológica e sexual contra elas ou seus filhos. Foi observada a presença de violência nas famílias de origem das mulheres e dos agressores. Os dados levantados confirmam estudos que apontam que a maioria dos casos de agressão contra a mulher ocorre em seus próprios lares. Observou-se também que o uso de álcool e drogas e a presença de violência anterior nas famílias podem ser apontados como fatores de risco para a perpetuação do fenômeno. Destaca-se a importância de projetos de prevenção e intervenção junto a essa população.
\end{abstract}

Unitermos: Mulher. Política social. Psicologia forense. Violência contra a mulher.

\begin{abstract}
The aim of this study was to carry out a survey of the cases seen by the psychological service of a women's police station unit, in a city in the metropolitan area of Porto Alegre, between 2006 and 2008. The empirical sample consists of 351 women aged between 12 and 78 . The types of violence perpetrated included physical, psychological and/or sexual abuse against women or their children. The existence of previous violence, in the victims' and aggressors' families of origin, was observed. The data collected corroborated studies that demonstrate that the majority of the cases of violence against women occur in their own homes. It was also noted that the use of alcohol or drugs and the occurrence of previous violence in the families can be pointed to as risk factors. The importance is emphasized of prevention and intervention projects for this population.
\end{abstract}

Uniterms: Women. Public policy. Forense psychology. Violence against Women.

$\boldsymbol{\nabla \nabla \boldsymbol { \nabla } \nabla}$

1 Artigo elaborado a partir da dissertação de L.M. GADONI-COSTA, intitulada "Violência domestica: vitrimização e enfrentamento". Universidade Federal do Rio Grande do Sul, 2010.

2 Universidade Federal do Rio Grande do Sul, Programa de Pós-Graduação em Psicologia. R. Ramiro Barcelos, 2600, Santa Cecília, 90035-003, Porto Alegre, RS, Brasil. Correspondência para/Correspondence to: L.M. GADONI-COSTA. E-mail: <lilamariacosta@gmail.com>.

3 Psicóloga. Porto Alegre, RS, Brasil. 
Este trabalho tem por objetivo apresentar os resultados do levantamento dos casos atendidos no setor de Psicologia de uma Delegacia para a Mulher, em município da região metropolitana de Porto Alegre (RS), no período de 2006 a 2008. A violência contra a mulher passou a fazer parte da luta dos movimentos feministas no Brasil de forma mais intensa a partir das décadas de 1970 e 1980, ocasião em que o governo propôs as primeiras políticas públicas na área. A literatura especializada tem tratado essa forma de violência como uma questão complexa e multifacetada, que viola os direitos humanos das mulheres vitimizadas (Gadoni-Costa \& Dell'Aglio, 2009; Grossi \& Aguinsky, 2001; Rovinski, 2004). Também considerado um problema de saúde pública, a violência contra a mulher provoca perdas significativas na saúde física e mental das vítimas. Além disso, as relações sociais ficam prejudicadas e deixam de funcionar como rede de apoio (Couto, Schraiber, d'Oliveira \& Kiss, 2006; Monteiro \& Souza, 2007). Devido ao número crescente de notificações, o fenômeno passou a ser amplamente estudado por diferentes áreas do conhecimento. O implemento de políticas públicas e serviços de atendimento tem sido proporcional ao aumento da demanda.

A partir da criação das delegacias especializadas, a mulher passou a ter um "ponto de partida" na busca de apoio e acesso à rede pública e privada. Segundo Brandão (2004), para que as delegacias funcionem com eficácia, precisam operar de forma integrada e oferecer um atendimento qualificado, evitando a revitimização da mulher que chega até ali. Pasinato (2006) salienta a importância do primeiro atendimento dado à mulher e do papel que esse momento passar a ter sobre as decisões que ela tomará quanto a permanecer na relação violenta ou buscar novas saídas para sua vida.

\section{A delegacia para a mulher} coletivas ocorridas em vários países, nas últimas décadas, desencadeou um processo que tirou a violência contra a mulher do âmbito doméstico, tornando-a pública (Grossi, Tavares \& Oliveira, 2008). Em 1985, foi criada em São Paulo a primeira delegacia especializada no atendimento à mulher. Atualmente, são mais de 300, em praticamente todos os Estados do Brasil, com diferentes denominações: Delegacia de Defesa da Mulher
(DDM), Delegacia para a Mulher (DM) e Delegacia Especializada no Atendimento à Mulher (DEAM). Apesar dessas diferenças, estudos apontam que o perfil das usuárias é semelhante, bem como as representações dos policiais sobre seu trabalho e sobre o público atendido (Debert \& Oliveira, 2007). Segundo Rifiotis (2004), o tipo de atividade que efetivamente se desenvolve nas delegacias especializadas vai além de criar condições para a resolução de conflitos conjugais. Monteiro (2005) salienta que o momento do registro de ocorrência é singular. A mulher que decide denunciar necessita de apoio e acompanhamento, pois nem sempre está pronta para sair da situação de violência.

Estudos apontam que alguns mecanismos funcionam como apoio e fortalecem a mulher no momento de decisão sobre a denúncia, como a Lei 11.340/2006, sancionada em 7 de agosto de 2006 (Debert \& Oliveira, 2007). Essa lei foi batizada como "Lei Maria da Penha", para homenagear uma cearense que ficou paraplégica após ser agredida pelo marido. Graças à militância de grupos de defesa dos direitos humanos junto à Comissão Interamericana de Direitos Humanos da Organização dos Estados Americanos, o marido de Maria da Penha foi punido, dezenove anos após a ocorrência do crime (Debert \& Oliveira, 2007). Conforme as autoras, com a Lei Maria da Penha a violência doméstica deixou de ser um crime de menor potencial ofensivo. A pena máxima passou a ser de três anos de detenção, e o afastamento do agressor pode ser solicitado através de medidas protetivas quando a mulher está em situação de risco. Se as medidas forem desobedecidas, é admitido o pedido de prisão preventiva do agressor. No entanto, considerando que a lei é muito ampla, entende-se que há ainda a necessidade de padronizar sua aplicação, de forma que não ocorram distorções na interpretação nos diferentes âmbitos em que ela é aplicada. Além disso, considerando que a população em geral desconhece definições sobre o que é a violência doméstica, também se faz necessário um trabalho de conscientização para que mais pessoas possam se utilizar da lei, de forma a ter benefícios e ficar protegidas.

A Delegacia para a Mulher (DM) em que foram coletados os dados deste estudo foi inaugurada em março de 2006, visando atender a crescente demanda dos casos de violência contra a mulher naquele município. O setor de Psicologia foi criado a partir de uma par- 
ceria entre a DM e a Prefeitura Municipal, que disponibilizou dois técnicos (uma psicóloga e uma assistente social) para realizar os atendimentos no local. Essa parceria se deu através do entendimento de que a polícia também pode ter uma função social que vai além da repressão ao crime, e reforça a ideia de que a vontade política e o diálogo entre os diversos setores viabilizam ações concretas. Grossi et al. (2008) apontam que essas parcerias possibilitam que se formalizem papéis e vínculos entre serviços e instituições públicas. Dessa forma, uma rede de atendimento que visa à assistência integral se constitui, correspondendo a um conceito de colaboração e integração de serviços, que é recomendado pelas experiências mundiais e locais na área da violência. A partir daí, foi criado o setor de Psicologia na Delegacia, que funciona em um prédio contíguo ao da Polícia Civil e conta, como recursos humanos, além das técnicas, com a delegada titular, três policiais, três estagiários (dois de ensino médio e uma de Psicologia) e uma secretária.

Ao chegar à DM, a mulher toma conhecimento da existência do serviço de Psicologia e pode solicitar atendimento. Outra possibilidade é o encaminhamento da vítima pelos policiais, conforme o estado emocional em que se encontra na ocasião do registro de ocorrência. Nesse local também são realizados atendimentos individuais e em grupo. Após o acolhimento ou entrevista inicial, as mulheres podem permanecer em atendimento na DM ou ser encaminhadas para a rede pública. Nos atendimentos psicológicos, as maiores queixas são relativas ao parceiro. Muitas dessas mulheres ainda não se sentem em condições de romper o ciclo de violência e procuram a delegacia para orientação ou apenas para ter uma escuta diferenciada, para um "desabafo".

Além das mulheres vítimas, são atendidos seus filhos (crianças e adolescentes) ou familiares próximos, quando solicitado por elas. Algumas dessas crianças e adolescentes apresentam sintomas decorrentes da situação de violência doméstica presente na família. Os atendimentos estendem-se também aos casos de abuso sexual e violência contra crianças e adolescentes, bem como elaboração de laudos e avaliação psicológica por requisição judicial.

\section{Definições conceituais}

Violência doméstica é aquela praticada no âmbito privado, perpetrada por um membro da família que conviva com a vítima ou tenha relacionamento afetivo com ela. Pode envolver diferentes tipos de maus-tratos, como violência psicológica, violência física e violência sexual, além de negligência e abandono. Por violência psicológica entende-se toda ação ou omissão que cause dano à autoestima ou ao desenvolvimento da pessoa vitimizada. Segundo o Ministério da Saúde (Brasil, 2001), é a modalidade mais difícil de ser identificada, caracterizando-se por humilhações, chantagem, ameaças, discriminação, crítica ao desempenho sexual e privação de liberdade. Pode levar ao isolamento social com afastamento dos amigos e familiares, ou impedir que a vítima faça uso de seu próprio dinheiro. Suas consequências são graves e podem levar ao adoecimento e, em casos mais extremos, ao suicídio (Brasil, 2001).

A violência física é o dano ou a tentativa de causá-lo, por meio da força física ou de uso de objeto (arma, instrumento) que provoque lesões externas (hematomas, cortes, feridas) ou internas (hemorragia, fraturas). A violência sexual é caracterizada como um ataque em que o agressor obriga a vítima a realizar práticas sexuais por meio de força ou intimidação, sem seu consentimento. As situações podem envolver estupro, prostituição forçada e coerção à pornografia, entre outras (Rovinski, 2004; Sacramento \& Rezende, 2006). Essas formas de violência têm uma complexa rede de associação, que pode envolver uso de álcool e/ou outras drogas, baixa escolaridade e histórico de violência na família de origem, entre outros (Cortez, Padovani \& Williams, 2005; d'Oliveira et al., 2009). Entretanto, é importante salientar que nenhum desses fatores é, por si só, causa da violência contra a mulher.

A partir dessas considerações e entendendo-se que propostas de prevenção e intervenção em situações de violência precisam levar em conta as características da população alvo, este estudo buscou conhecer melhor o perfil das mulheres atendidas na Delegacia para a Mulher. Dessa forma, procurou-se levantar as características presentes nos casos, observando-se as interações entre elas.

\section{Método}

Foi realizado estudo documental, a partir das fichas de atendimento do setor de Psicologia da Delegacia para a Mulher na região metropolitana de Porto 
Alegre, relativas ao período de março de 2006 (inauguração da delegacia) a dezembro de 2008. O estudo foi aprovado pelo Comitê de Ética em Pesquisa do Instituto de Psicologia da UFRGS, sob protocolo n 099/2008, em 14/4/2009, tendo a delegada titular assinado o Termo de Concordância da Instituição para utilização do banco de dados.

As fichas contêm as principais informações do caso, incluindo idade, escolaridade, profissão, emprego, estado civil, situação conjugal, número de filhos, presença ou não de família extensa (avós, tios, primos etc.), ocorrência de violência na família de origem da mulher e na família do agressor, uso de álcool e/ou outras drogas pelo agressor, uso de medicação psiquiátrica pela vítima e motivo da procura. Foram selecionadas para este estudo todas as fichas que se referiam a mulheres e adolescentes, a partir de 12 anos, e que tinham como motivo de atendimento alguma queixa de violência perpetrada por um homem. Dessa forma, foram excluídas fichas referentes a atendimentos de homens, crianças e testemunhas, além de casos de violência perpetrada por outra mulher ou outras situações que não se configuram como violência contra a mulher.

Os dados relativos ao agressor foram categorizados como: companheiro, pai, padrasto, filho/irmão, outro parente, vizinho/conhecido, e desconhecido. As categorias relacionadas ao motivo do atendimento foram: violência física contra a própria mulher; violência psicológica contra ela; violência contra os filhos; abuso sexual contra os filhos; e violência sexual contra a mulher. Foram considerados casos de violência psicológica aqueles em que havia relato de ocorrência de ameaça, chantagem, humilhação, agressão verbal e restrição de liberdade. A escolaridade das participantes foi classificada desde ensino fundamental incompleto até ensino superior completo. As profissões foram divididas em dona de casa ou sem profissão definida, serviços ₹ gerais, indústria e comércio, professoras e funcionárias ? públicas. A situação de vida atual incluiu: mora sozinha; com companheiro; com companheiro e filhos; com filhos; com familiares; e outros.

Os dados das fichas foram categorizados, buscando-se consenso entre três juízes para a classificação das informações nas categorias definidas a partir da análise de conteúdo (Bardin, 1979) do material das fichas.

222 As variáveis qualitativas foram descritas através de frequência absoluta e relativa, enquanto as variáveis quantitativas foram mensuradas através de média e desvio-padrão. Para avaliar a associação entre as variáveis qualitativas foi utilizado o Teste de Associação Qui-quadrado. Na modelagem multivariada foi utilizada a Regressão Logística a partir das variáveis significativas na análise bivariada. Os dados foram analisados no software SPSS e o nível de significância adotado foi de $5 \%(p \leq 0,05)$.

\section{Resultados e Discussão}

A amostra deste estudo foi composta por 351 fichas de mulheres com idade entre 12 e 78 anos, com média de 36,95 (Desvio-Padrão - DP=13,09). Observou-se maior frequência de casos na faixa etária entre 24 e 45 anos, correspondente a 59\% dos casos. Esta faixa etária também é citada em outros estudos, sendo associada por alguns autores a um período de maior atividade sexual e reprodutiva (Adeodato, Carvalho, Siqueira \&Souza, 2005; Monteiro, Araújo, Nunes, Lustosa \& Bezerra, 2006).

A escolaridade variou entre ensino fundamental incompleto e curso superior completo, sendo que 53,7\% das mulheres não completaram o ensino fundamental. Quanto à ocupação, 43,3\% têm empregos em comércio e indústria, 32,5\% são donas de casa ou não têm profissão, 17,4\% trabalham em serviços gerais e 6,8\% são funcionárias públicas ou professoras. Estudos apontam que mulheres que desenvolvem atividade profissional remunerada buscam estratégias mais eficazes para enfrentar a situação de violência, além de demonstrar uma atitude mais positiva diante da vida e maior grau de autonomia e autoestima (Debert \& Oliveira, 2007; Rabello \& Caldas Júnior, 2007). Segundo Debert e Oliveira, a clientela das delegacias especializadas em diferentes cidades e regiões do Brasil apresenta uma homogeneidade no seu perfil. Em geral, são mulheres de classe popular, baixo nível de instrução, predominando ensino fundamental completo ou incompleto. No item profissão, o que mais aparece é "do lar" ou "doméstica".

A baixa escolaridade é apontada por alguns autores como um dos fatores que favorecem a situação de violência, visto que mulheres mais esclarecidas tendem a ter menor grau de tolerância à situação (Adeodato et al., 2005; Rabello \& Caldas Júnior, 2007). Isso não significa 
que mulheres de classes mais favorecidas e com mais anos de escolaridade também não enfrentem situações de violência. A diferença é que essas mulheres dispõem de recursos que possibilitam encontrar ajuda em consultórios e escritórios particulares de médicos, psicólogos e advogados. Essas alternativas levam a uma sub-representação nas denúncias, fazendo com que as situações de violência contra a mulher sejam diretamente associadas à pobreza.

Apenas 26,2\% das mulheres afirmaram ser casadas no papel. Estudo de d'Oliveira et al. (2009) apontou que viver sem união formal associou-se à violência por parceiro íntimo. A valorização do casamento formal, aliado à castidade feminina, apareceu como possível fator influenciador na associação entre violência conjugal e união informal em parte da amostra pesquisada por esses autores.

Quanto a filhos, 52,7\% das mulheres tinham entre dois e três filhos, e 16,8\% não os tinham. Segundo Rabello e Caldas Júnior (2007), estudos que indicam um menor número de filhos estão em consonância com dados do Instituto Brasileiro de Geografia e Estatística (2005), que sugerem uma queda da fecundidade da mulher brasileira. Esse declínio deve-se a diversos fatores, entre os quais a inserção cada vez maior da mulher no mercado de trabalho (Rabello \& Caldas Júnior, 2007). Na ocasião em que compareceram à delegacia para registrar ocorrência como vítimas de violência, 50,4\% das mulheres viviam com companheiro e filhos.

Os tipos de violência perpetrados foram: violência psicológica (82,9\%), violência física (53,0\%), abuso sexual contra os filhos (15,7\%), violência sexual contra a própria $(11,1 \%)$ e violência física contra os filhos (8,5\%). Destaca-se que essas categorias não são excludentes e que, na maioria dos casos em que houve violência física e sexual, houve também relato de violência psicológica
(Tabela 1). Silva, Coelho e Caponi (2007) salientam que, embora haja diferença entre os vários tipos de violência, elas se entrelaçam e se misturam de diferentes maneiras.

Em pesquisa realizada por Silva (2005), em um centro de atendimento a vítimas de crimes, dentre as formas atendidas de violência doméstica, a violência psicológica associada à física foi a que mais se evidenciou. Para Silva et al. (2007) é difícil entender a ocorrência da violência física sem a presença da violência psicológica, visto que ela acompanha todas as manifestações da violência intrafamiliar.

O fato de essa forma de violência ser menos enfatizada deve-se à prioridade que é dada às consequências físicas em detrimento das psicológicas, que são igualmente graves. A violência psicológica afeta, além da vítima, a todos que convivem com ela de forma direta, como os filhos ou outros familiares. A literatura sugere que é preciso repensar sobre a dicotomia entre dano físico e psicológico. O fenômeno da violência contra a mulher produz um efeito bidimensional que causa danos físicos e emocionais em suas vítimas (Melo, Caldas, Carvalho \& Lima, 2005; Rovinski, 2004).

Os dados levantados apontaram que em 70,1\% dos casos o agressor era o companheiro da vítima, e que em apenas 3,1\% dos casos era desconhecido. Segundo a Organização Mundial da Saúde, uma em cada seis mulheres no mundo sofre violência doméstica, sendo que em 60,0\% dos casos a violência foi perpetrada por marido ou companheiro (Organização Mundial da Saúde, 2005).

Em consonância com a literatura, os dados da Tabela 1 indicam predomínio do companheiro como agressor nos casos de violência física e psicológica contra a mulher, e física e sexual contra os filhos. O lar, antes considerado um lugar seguro, passou a representar risco para as mulheres vítimas da violência doméstica

Tabela 1. Percentuais por tipo de violência e agressores. Porto Alegre (RS), 2006-2008.

\begin{tabular}{|c|c|c|c|c|c|c|c|}
\hline \multirow{2}{*}{ Tipo violência } & Companheiro & Pai & Padrasto & Filho/irmão & Outro parente & Vizinho/conhecido & Desconhecido \\
\hline & \multicolumn{7}{|c|}{$\%$} \\
\hline Física (n=186) & 83,9 & 1,6 & 3,2 & 7,0 & 1,1 & 1,6 & 1,6 \\
\hline Psicológica $(n=291)$ & 77,3 & 4,5 & 3,8 & 6,5 & 3,4 & 2,7 & 1,7 \\
\hline Sexual $(n=39)$ & 23,1 & 10,3 & 25,6 & 0 & 5,1 & 20,5 & 15,4 \\
\hline Física contra filhos ( $n=30)$ & 93,3 & 0 & 0 & 0 & 0 & 6,7 & 0 \\
\hline Sexual contra filhos $(n=55)$ & 52,7 & 0 & 3,6 & 1,8 & 16,4 & 18,2 & 7,3 \\
\hline
\end{tabular}


(Gadoni-Costa \& Dell'Aglio, 2009; Grossi et al., 2008). Em pesquisa realizada por esses autores, mulheres em situação de violência se referiram a seus agressores com sendo as únicas pessoas significativas com que podiam contar, indicando importante isolamento social em que o homem agressor é a única referência em suas vidas.

Nos casos de violência sexual, o agressor que mais aparece é o padrasto, no caso das vítimas mais jovens, seguido pelo companheiro e vizinho/conhecido. Dados semelhantes foram encontrados em estudo do Centro de Estudos Superiores de Maceió (CESMAC), realizado entre os anos de 2002 e 2007. Entre os 311 casos de abuso sexual contra crianças e adolescentes pesquisados, o padrasto apareceu em primeiro lugar como agressor, seguido por outros parentes. O agressor era, em geral, vinculado à família e conhecido da vítima (Observatório da Mulher, 2009).

Os dados apontaram que 57,0\% dos agressores e 47,0\% das mulheres atendidas possuíam famílias de origem com histórico de violência (Tabela 2). Foi observada uma associação significativa entre ter família com histórico de violência e ter companheiro com histórico de violência na família $\left(\chi^{2}=14,26 ; g l=1 ; p<0,001\right)$. Assim, observou-se que entre as mulheres com histórico de violência na família, 112 (67,9\%) tinham companheiros que também apresentavam famílias com histórico de violência, enquanto das 186 mulheres sem histórico de violência, 88 (47,3\%) tinham companheiros com histórico de violência na família. Conforme Negrão et al. (2005), presenciar situações de violência no âmbito doméstico de forma reiterada pode levar à crença de que a violência conjugal é algo natural. Dessa forma, a mulher deveria se submeter ao homem por não existirem outras formas de relação entre um casal.

Diversos autores corroboram esses dados e salientam que aspectos relacionados às experiências de vida das mulheres têm sido identificados como fatores de risco. As experiências vividas na família de origem têm mostrado consistente associação com violência doméstica posterior (d'Oliveira et al., 2009; Santos \& Dell'Aglio, 2008). Testemunhar violência perpetrada contra a mãe no âmbito doméstico e sofrer violência física cometida pelos pais pode aumentar o risco de sofrer essa forma de violência na vida adulta. Segundo d'Oliveira et al. (2009), essas vivências podem diminuir a

224 capacidade das mulheres de se protegerem no futuro através de apoio familiar, além de banalizar a violência nas relações conjugais, sugerindo que esse padrão não pode ser modificado. "As relações e os comportamentos entre os membros da família terão na violência não só uma inspiração, mas também a pedra sobre a qual serão construídos" (Melo et al., 2005, p.205).

Quanto ao uso de álcool/drogas pelos agressores, constatou-se que 59,3\% deles eram usuários dessas substâncias, sendo que 123 deles (59,1\%) perpetraram violência física e 183 (88,0\%), violência psicológica (Tabela 3). Foi observada uma associação significativa entre o uso de álcool/drogas e violência física $\left(\chi^{2}=7,14 ; \mathrm{gl}=1\right.$; $p=0,008)$ e entre uso de álcool/drogas e violência psicológica $\left(\chi^{2}=8,42 ; g l=1 ; p=0,004\right)$.

O abuso de álcool tem um profundo impacto sobre a família do dependente. Todos os membros da estrutura familiar sofrem as consequências, embora crianças e adolescentes sejam os mais afetados. Para Melo et al. (2005), quanto mais intensa a violência física ou verbal em situações que envolvem alcoolismo, mais graves serão os prejuízos, que podem compreender depressão, comportamento antissocial, desarmonia conjugal, ansiedade e resolução inadequada de problemas na vida adulta.

O alcoolismo leva a importantes modificações na personalidade, que podem afetar as relações sociais do sujeito de forma negativa. Conforme estudos de

Tabela 2. Percentuais de ocorrência da violência na família de origem da mulher e do agressor. Porto Alegre (RS), 2006-2008.

\begin{tabular}{lccc}
\hline \multirow{2}{*}{$\begin{array}{l}\text { Violência na família } \\
\text { de origem do agressor }\end{array}$} & \multicolumn{3}{c}{ Violência na família de origem da mulher } \\
\cline { 2 - 4 } Não & Não & Sim & Total \\
Sim & 52,7 & 32,1 & 43,0 \\
& 47,3 & 67,9 & 57,0 \\
\hline
\end{tabular}

Tabela 3. Percentuais de casos com uso de álcool/drogas e violência física e psicológica. Porto Alegre (RS), 2006-2008.

\begin{tabular}{lllll}
\hline \multirow{2}{*}{ Violência } & \multicolumn{3}{c}{ Uso álcool/drogas } \\
\cline { 3 - 5 } & & Não & Sim & Total \\
\hline Física & Não & 55,9 & 40,9 & 47,0 \\
& Sim & 44,1 & 59,1 & 53,0 \\
Psicológica & Não & 24,5 & 12,0 & 17,1 \\
& Sim & 75,5 & 88,0 & 82,9 \\
\hline
\end{tabular}


Narvaz (2002), o alcoolismo tem sido descrito na literatura como uma importante variável relacionada com a violência conjugal, que desencadeia conflitos e serve para justificar o comportamento abusivo. Além disso, as mulheres de alcoolistas ficam sobrecarregadas emocionalmente devido ao empobrecimento ou ausência de apoio por parte do parceiro. A autora destaca ainda a associação entre violência conjugal, alcoolismo e permanência das mulheres em relações violentas, além de citar estudos que associam alcoolismo e abuso sexual intrafamiliar, com estimativa de que um grande percentual de vítimas dessa forma de violência provém de lares de alcoolistas.

Para analisar de forma multivariada a violência física e psicológica, foram realizadas regressões logísticas a partir das variáveis significativas na análise bivariada. No modelo ajustado para violência física (Tabela 4), foi significativo apenas o uso de álcool/drogas do agressor, de forma que os agressores usuários de álcool/ drogas apresentaram 76,5\% mais chance de perpetrar violência física contra a mulher, quando comparados com os não usuários ( $R C=1,765$; IC95\% 1,143 - 2,725).

No modelo ajustado para violência psicológica (Tabela 5), foram significativos o uso de álcool/drogas e o histórico de violência na família de origem do agressor. Os agressores usuários de álcool/drogas apresentam 124,0\% mais chance de cometer violência psicológica contra a mulher quando comparados com os não usuários ( $R C=2,242 ;$ IC95\% 1,267 - 3,969), e os agressores com histórico de violência na família de origem apresentaram 80,1\% mais chance de cometer violência psicológica quando comparados com os sem histórico de violência na família de origem ( $R C=1,801$; IC95\% $1,018-3,185)$
O uso de álcool e/ou outras drogas pode ser explicado, conforme Rovinski (2004), por sua função desinibidora na conduta dos agressores ou ainda como uma forma de minimizar a responsabilidade por tais atos. A autora salienta que uma das hipóteses para que álcool e violência se associem é o fato de que ambos têm fatores preditivos comuns, como por exemplo, uma personalidade impulsiva.

Entre as mulheres da amostra, 34,2\% informaram fazer uso de medicamentos psiquiátricos, principalmente antidepressivos e ansiolíticos. A literatura aponta que mulheres em situação de violência têm mais chances de desenvolver doenças psiquiátricas e, consequentemente, fazer uso de psicofármacos (Adeodato et al, 2005; Rovinski, 2004; Strey, 2007). Quadros de depressão, ansiedade e sintomas fóbicos são citados por Adeodato et al. (2005) como características de síndromes clínicas encontradas em mulheres agredidas. Rovinski (2004) faz referência a estudos que citam, além dessas, transtorno de estresse pós-traumático e transtorno obsessivo-compulsivo. Para Meneghel e Hennington (2007), o estado de fragilidade e vulnerabilidade que decorre da situação de violência causa efeitos negativos permanentes na autoestima e na autoimagem da mulher, deixando-a insegura sobre seu valor e com menos condições de se proteger. Essa fragilidade também propicia a aceitação da vitimização como uma condição natural de ser mulher.

\section{Considerações Finais}

A caracterização de serviços de atendimento à mulher e o levantamento do perfil das usuárias, objetivo

Tabela 4. Regressão logística para violência física. Porto Alegre (RS), 2006-2008.

\begin{tabular}{lccrcr}
\hline & Razão de chance & Intervalo de 95\% de confiança & $p$ & 2,725 & 0,010 \\
\hline Uso álcool/drogas & 1,765 & 1,143 & 2,329 & 0,063 \\
Violência família de origem agressor & 1,513 & 0,983 & 0 \\
\hline
\end{tabular}

Tabela 5. Regressão logística para violência psicológica. Porto Alegre (RS), 2006-2008.

\begin{tabular}{|c|c|c|c|c|}
\hline \multirow[b]{2}{*}{ Uso álcool/drogas } & \multirow{2}{*}{$\frac{\text { Razão de chance }}{2,242}$} & \multicolumn{2}{|c|}{ Intervalo de 95\% de confiança } & \multirow{2}{*}{$\frac{p}{0,006}$} \\
\hline & & 1,267 & 3,969 & \\
\hline Violência família de origem agressor & 1,801 & 1,018 & 3,185 & 0,043 \\
\hline
\end{tabular}


a que se propôs este estudo, são fundamentais para que os profissionais envolvidos tenham um maior entendimento acerca das causas, fatores associados e consequências do fenômeno da violência contra a mulher. Somente a partir da compreensão, tanto da violência, quanto da mulher que a vivencia, é que esses serviços serão realmente especializados, e assim poderão oferecer às suas usuárias um acolhimento adequado e eficaz. Esse acolhimento envolve, além da compreensão, o respeito ao tempo de que essa mulher muitas vezes necessita para tomar a decisão certa. Envolve também uma dose de tolerância por parte dos profissionais envolvidos nas situações em que a mulher retoma o relacionamento com seu agressor, não porque "gosta de apanhar", mas porque ainda não percebeu que existem outras formas de se relacionar. Nesse sentido, destaca-se a necessidade de capacitação a esses profissionais, tendo em vista que o número de delegacias especializadas no Brasil aumentou, mas a formação de profissionais para atuação na área ainda é escassa e necessita de investimentos.

Os principais resultados deste estudo apontam para o predomínio da violência psicológica, entrelaçada com outros tipos de violência. Em consonância com a literatura, o principal agressor e o abusador sexual encontram-se dentro de casa. A violência na família de origem e o uso de álcool e outras drogas foram associados à violência atual e podem ser considerados preditores do fenômeno, de acordo com os dados deste levantamento, permitindo dessa forma que se tenha uma compreensão mais ampla do fenômeno, no contexto de realização deste estudo.

Quanto às limitações deste estudo, a primeira refere-se ao modelo da ficha utilizada, restrito ao levantamento de poucas variáveis. Outros dados, além dos sociodemográficos, possibilitariam uma investigação mais aprofundada sobre a população atendida na delegacia em questão e sobre os agressores. Dessa forma, sugere-se que os profissionais que trabalham nas delegacias possam se organizar no sentido de coletar dados mais específicos das usuárias do serviço, permitindo uma melhor investigação sobre esta realidade. Outra limitação diz respeito ao contingente analisado, composto em sua maioria por mulheres de baixa escolaridade e pertencentes a camadas de baixa renda. Este dado demonstra que o sistema de atendimento abrange apenas uma parcela da população vítima de violência, e que seria importante que as políticas públicas pudessem também atingir mulheres com maior escolaridade e melhores condições sociais e econômicas.

Destaca-se a importância de identificar as variáveis relacionadas à violência contra a mulher, assim como as associações entre as mesmas, que se constituem fatores de risco para essa população. Os achados relacionados ao histórico de violência nas famílias de origem da mulher e do agressor levam à reflexão sobre a necessidade de intervenções também junto aos filhos desses casais, de forma a evitar a perpetuação do ciclo de violência. Nesse sentido, sugerem-se programas de capacitação dirigidos a profissionais, nos municípios que contam com centros de referência no atendimento à mulher, a fim de estender os serviços aos filhos, casais e famílias em situação de violência. Projetos que envolvam atendimentos grupais a essas mulheres e seus familiares devem ser previstos também na rede de assistência social e da saúde, assim como nas políticas públicas direcionadas à mulher. Da mesma forma, são necessárias ações no sentido de fortalecer as redes sociais de apoio disponíveis, bem como considerar o agressor e o uso de álcool e outras drogas como foco de atenção e intervenção urgente.

O caminho para que os serviços de atendimento à mulher, em especial as delegacias, que são o "ponto de partida" para enfrentar a violência, cheguem a uma situação ideal ainda é longo e repleto de percalços. Espera-se, com esse estudo, contribuir de alguma forma para que essa situação ideal seja alcançada. Espera-se também que as mulheres em situação de violência, como as que compuseram esta amostra, encontrem, a partir da escuta cuidadosa de profissionais, um "ponto de chegada", bem distante da situação em que se encontravam.

\section{Referências}

Adeodato, V., Carvalho, R., Siqueira, V., \& Souza, F. (2005). Qualidade de vida e depressão em mulheres vítimas de seus parceiros. Revista de Saúde Pública, 39 (1), 108-113.

Bardin, L. (1979). Análise de conteúdo. Lisboa: Edições 70.

Brandão, E. R. (2004). Nos corredores de uma delegacia da mulher:umestudo etnográfico sobre as mulheres eaviolência conjugal. Dissertação de mestrado não-publicada, Instituto de Medicina Social, Universidade do Estado do Rio de Janeiro. 
Brasil. Ministério Público. (2001). Violência intrafamiliar: orientações para a prática em serviço. Brasília: Secretaria de Políticas de Saúde.

Cortez, M. B., Padovani, R. C., \& Williams, L. C. A. (2005). Terapia de grupo cognitivo-comportamental com agressores conjugais. Estudos de Psicologia (Campinas), 22 (1), 13-21. doi: 10.1590/S0103-166×2005000100003.

Couto, M. T., Schraiber, L., d'Oliveira, A. F., \& Kiss, L. B. (2006). Concepções de gênero entre homens e mulheres de baixa renda e escolaridade acerca da violência contra a mulher, São Paulo, Brasil. Ciências e Saúde Coletiva, 11 (Suppl. 0), 1323-1332.

d'Oliveira, A. F., Schraiber, L., França-Junior, I., Ludemir, A., Portella, A., Diniz, C., Couto, M. T., et al. (2009). Fatores associados à violência por parceiro íntimo. Revista de Saúde Pública, 43 (2), 299-310.

Debert, G. G., \& Oliveira, M. B. (2007). Os modelos conciliatórios de solução de conflitos e a "violência doméstica". Cadernos Pagu, 29, 305-337.

Gadoni-Costa, L. M., \& Dell'Aglio, D. D. (2009). Mulheres em situação de violência doméstica: vitimização e coping. Gerais: Revista Interinstitucional de Psicologia, 2 (2), 151-159.

Grossi, P. K., \& Aguinsky, B. G. (2001). Por uma nova ótica e uma nova ética na abordagem da violência contra mulheres nas relações conjugais. In P. K. Grossi \& G. C. Verba (Org.), Violências e gênero: coisas que a gente não gostaria de saber (pp.19-45). Porto Alegre: EDIPUCRS.

Grossi, P. K., Tavares, F., \& Oliveira, S. B. (2008). A rede de proteção à mulher em situação de violência doméstica: avanços e desafios. Athenea Digital, 14, 267-280. Recuperado em julho 1, 2009, disponível em <http:// psicologiasocial.uab.es>.

Instituto Brasileiro de Geografia e Estatística. (2005). Síntese dos Indicadores Sociais 2005. Pesquisa Nacional por Amostra de Domicílios. Recuperado em agosto 28, 2010, disponível em <http://www.ibge.gov.br>.

Melo, Z., Caldas, M. T., Carvalho, M., \& Lima, A. T. (2005). Família, álcool e violência em uma comunidade da cidade do Recife. Psicologia em Estudo, 10 (2), 201-208.

Meneghel, S. N., \& Hennington, E. A. (2007). A rota crítica das mulheres no Brasil: aspectos preliminares do estudo em São Leopoldo. In S. N. Meneghel (Org.), Rotas críticas: mulheres enfrentando a violência (pp.51-61). São Leopoldo: Unisinos.

Monteiro, C. F. S. (2005). Marcas no corpo e na alma de muIheres que vivenciam a violência conjugal: uma compreensão pela enfermagem. Tese de doutorado não-publicada, Programa de Pós-Graduação em Enfermagem, Universidade Federal do Rio de Janeiro.

Monteiro, C. F. S., \& Souza, E. O. (2007). Vivência da violência conjugal: fatos do cotidiano. Texto Contexto Enfermagem, $16(1), 26-31$.
Monteiro, C. F. S., Araújo, T., Nunes, B., Lustosa, A., \& Bezerra, C. (2006). A violência contra a mulher atendida em unidade de urgência: uma contribuição da enfermagem. Escola Anna Nery Revista de Enfermagem, 10 (2), 273-279.

Narvaz, M. (2002). Quem são as mães das vítimas de incesto? Insight-Psicoterapia, 132 (133), 9-13.

Negrão, T., Prá, J. R., Fernandes, A., Werba, G., Azevedo, I., Mattos, L., Oliveira, M. L., et al. (2005). Dossiê: violência de gênero contra meninas. Porto Alegre: Rede Nacional Feminista de Saúde.

Observatório da Mulher. (2009). Abuso sexual. Recuperado em agosto 10, 2009, disponível em <http://observatorio damulher.org.br>.

Organização Mundial da Saúde. (2005). Violência contra a mulher. Geneva: OMS.

Pasinato, W. (2006). Atendimento às mulheres em situação de violência em Belo Horizonte. In E. Leocadio \& M. Libardoni (Org.), O desafio de construir redes de atenção às mulheres em situação de violência (pp.131-167). Brasília: AGENDE.

Rabello, P., \& Caldas Júnior, A. (2007). Violência contra a mulher, coesão familiar e drogas. Revista de Saúde Pública, 41 (6), 970-978.

Rifiotis, T. (2004). As delegacias especiais de proteção à mulher no Brasil e a "judiciarização" dos conflitos conjugais. Sociedade e Estado, 19 (1), 85-119.

Rovinski, S. L. R. (2004). Dano psíquico em mulheres vítimas de violência. Rio de Janeiro: Lumen.

Sacramento, L. T., \& Rezende, M. M. (2006). Violências: lembrando alguns conceitos. Aletheia, 24, 95-104.

Santos, S. S., \& Dell'Aglio, D. D. (2008). Compreendendo as mães de crianças vítimas de abuso sexual: ciclos de violência. Estudos de Psicologia (Campinas), 25 (4), 595-606. doi: 10.1590/S0103-166X2008000400014.

Silva, L. (2005). CEVIC: A violência denunciada. Dissertação de mestrado não-publicada, Programa de Pós-Graduação em Saúde Pública, Universidade Federal de Santa Catarina, Florianópolis.

Silva, L., Coelho, E., \& Caponi, S. (2007). Violência silenciosa: violência psicológica como condição da violência física doméstica. Interface: Comunicação, Saúde, Educação, 11 (21), 93-103.

Strey, M. N. (2007). O sofrimento emocional de mulheres em busca de ajuda. In S. N. Meneghel (Org.), Rotas críticas: mulheres enfrentando a violência (pp.97-104). São Leopoldo: Unisinos.

Recebido em: 28/8/2009

Versão final reapresentada em: 17/9/2010

Aprovado em: 8/10/2010 
